\title{
Targeting Young Consumers: How Family, Friends and Advertisement Shape Materialism in Pakistan
}

1Sabeen Zaman

Department of Management Sciences, COMSATS Institute of Information Technology Abbottabad, Pakistan MS Student; zamansabeen84@gmail.com

2Syed Afzal Moshadi Shah

Department of Management Sciences, COMSATS Institute of Information Technology Abbottabad, Pakistan Assistant Professor; afzalshah@ciit.net.pk

3Dr. S.A.F Hasnu

Department of Management Sciences, COMSATS Institute of Information Technology Abbottabad, Pakistan Professor; hasnu@ciit.net.pk

Doi:10.5901/mjss.2016.v7n4p703

Abstract

The purpose of the study is to investigate materialism among the youth of Pakistan. The paper examines the impact of age, self-esteem, social comparisons, and attention to television advertisement on materialistic values. The study employs an empirical approach using self-administered survey technique on the youth living in KPK province of Pakistan. The final sample consisted of 280 respondents between 14-22 years of age and registered student. Descriptive statistics, Correlation and Multiple regressions is estimated through SPSS (version 17.0). Results indicate age as a major antecedent in measuring materialism. Adolescents are found to be more materialistic as compare to young adults. The relationship between materialism and age is found negative. The influence of frequent communication with friends and social comparison of consumption was also found related with materialism. Attention to television advertisement is not found to be associated with developing materialism among young consumers. The inbuilt data limitation with cross sectional data is inevitable. Future research may employ longitudinal or qualitative i.e. interviewing techniques to secure data. The study imparts practical implication for parents, academic and professionals. The study is among the pioneer studies examining materialism among youth in Pakistan,

Keywords: Materialism, Materialistic values, adolescents, Youth, Ethics, Consumers

\section{Introduction}

The phenomena of materialism is a philosophical issues which can be traced back to early civilizations (Albert Lange, 1925). Individuals working together in a society develop and follow their particular social norms, values, beliefs, attitudes and behaviors (Kasser, 2002; Korten, 1999). One of the major forces behind the rise and fall of nations has somehow remained around the materialism factor.

Marketers around the world work vigorously try to attract and retain customers. Youth make a significant portion of their potential customers. Advertisement is criticized for promoting materialistic values among consumers especially among youth. It is a major concern among parents, educators, and policymakers to secure youth from developing materialist desires (Chan, 2013). Ethical concerns over advertisement have risen after the recent global economic crises. Hence, the materialism propagated through advertisement has reported to have negative social consequences. The role of media in promoting materialism among youth consumers is well grounded in the research (Churchill \& Moschis, 1979). The viewership of television (TV) has also been reported to have significant positive relationship on consumers' materialism.

The core issue while studying materialism among adolescents remains the effect of social comparison with friends (Chan \& Prendergast, 2007) while consumptions. He said that adolescents want to create their own identity and to create sovereignty from their parents, for that reason they want to make their own decisions. For the reason adolescents search for personal relations that give importance to their viewpoint and they make it sure that their feelings are valued. 
Materialists try to recognize them self by using materialistic achievements to increase their importance, that is why they are distinguished as people with low self-esteem (Kasser, 2002). As a result, materialism is driven by feelings of insecurity and low self-esteem (Chaplin \& John, 2007).

This study empirically examines the growing materialism among youth of Pakistan. It examines the role of family, friends and media. The basic objectives of the study are

- To investigate the role of media on developing consumer materialism

- To investigate the role of social comparison (SC) on consumer materialism

- To investigate the role of communication with family (CF) on consumer materialism

The paper is structured as follow: First, the review of the relevant literature on materialism, social comparison and communication with family. Second section contains discussion on the development of research hypotheses; next section explains the research methodology. Third, a Final section discusses the results, managerial implications and possible future research in the area is presented.

\section{Review of the Literature}

This section presents the latest literature on key variables used in the study i.e. materialism, individual influences, family influences, external influence. This section also develops some testable hypotheses in light of the literature.

\subsection{Materialism}

Economists explain materialism as the pursuit of one's own material well-being (Easterlin \& Crimmins, 1991). Whereas, in sociologists point of view materialism refers to a personal value that have a concern with material goods, comparison with others about material things, and the importance of making a profit, which is against the welfare of people or society (Beutel \& Marini, 1995). While in marketing the two famous gurus known for materialism are (Belk, 1985) and (Richins \& Dawson, 1992). According to Richins, materialism refers to a system of values, or an individual set of mind about gaining material possessions in life (Fournier \& Richins, 1991; Richins \& Dawson, 1992).On the other hand,(Belk, 1985) point of view is that materialism consists of three traits: possessiveness, non-generosity, and envy.

The concept of material values came from Richins, unlike Belk they do not take materialism as a personality variable or behavior, but they take it as a value (e.g., Fournier \& Richins, 1991; Richins \& Dawson, 1992; Richins, 1987, 1994). This value includes beliefs about the achievement of material centrality, material happiness and material success (Richins \& Dawson, 1992). According to him Material success refers to- the degree to which individuals take possessions as a sign of success and acquisition in life both in judging oneself and judging others. Where, Material happiness is defined as one's belief that possession is important for life satisfaction and wellbeing. However; recently (Viet Dung Trinh, 2012) worked on the idea of Richins and replace material centrality with material essentiality and material distinctiveness. The fuzzy idea of material centrality-the extent to which materialism is placed in the centre of one's life, has become more clear by material essentiality- a more real assessment of the idea that possessions are important and means of everything in life, and material distinctiveness-the idea that one use possession as a tool to look unique or stand out of crowd (Viet Dung Trinh, 2012). This study is working on the idea of Trinh (2012) to measure materialistic values of adolescent's.

Major literature on materialism is divided into two main streams. According to Richins, materialism refers to a system of values, or an individual set of mind about gaining material possessions in life. On the other hand Belk (1985) views materialism three component personality traits including possessiveness, non-generosity, and envy.

\subsection{Individual Influence}

Age and Gender: Consumer socialization is defined as a development process by which young people obtain consumerrelated skills, knowledge and attitudes (Bush, Martin, \& Clark, 2001). John (1999) model of consumer socialization is used in the present study to explain different stages of life as child grow-up to young consumer. Analytical stage: As the name refers at this stage children can analyze different dimensions. By this time children (starts from seven and end at eleven years), shift from perceptual to symbolic thoughts. Now they can understand their own and others perspective. At last, the Reflective stage comes (it starts from 11 to 16 years). Every dimension of a child is more developed. Now they are able to deal with difficult information. Now they pay much concentration to the social characteristics of being a customer (John, 1999).

In the topic of materialism, age is notorious in the literature (Chan, 2013b). Some previous studies say that 
materialistic value orientation decreases as age increases. Sheldon \& Kasser (2001) study say that elder people have less care about material possessions and feel more satisfied than younger people. A study performed by Ferle \& Chan (2008) show persuasion of marketing communication factors and social influence factor on children between 13 - 18 years old. Adolescents feel worried about their individuality, and they try to develop an affinity to define their selves through recognition, mostly by using material things and activities (Bindah \& Othman, 2011).Similarly another study by Baker \& Gentry (1996) finds that younger kid's compared more things with friends to know that who has more toys. On the other hand, some studies say that older people are more materialistic in comparison to younger adolescents (Chan, Zhang, \& Wang, 2006). John (1999) model say that importance of possessions is even understood by the youngest children of aged six to seven years but he does not state whether materialism increase or decreases with age. As such, age and experience are less important to be influenced by environmental and situational elements (Flurry \& Swimberghe, 2016). On the bases of studies, we proposed the following hypothesis,

H1: Age has a negative impact on materialism. Young adults are less materialistic as compared to adolescents.

Gender is another materialistic variable found in the literature. In western societies, boys are found to be more materialistic than girls (Achenreiner, 1997; Churchill \& Moschis, 1979; Goldberg et al., 2003; Moschis \& Churchill, 1978). However, in China, according to Chan (2013a) study, this variable doesn't make any change in gaining materialistic values.

\subsection{Self-esteem}

Self-esteem is a symbol related to self-confidence (Chan, 2013b). When children and adolescents gain materialistic values from experiences through society because of the insecurity feeling, than people who have low self-esteem will suffer high from high feeling of insecurity (Kasser, Ryan, Couchman, \& Sheldon, 2004). Consequently, they will be more chances to ripen materialistic values. Low self-esteem increases materialism as a way to satisfy needs related to esteem, insecurity and low self-worth (Kasser, 2008). Individuals suffering from low self-esteem engage with material things, which they see as being valuable for self-enhancement (Osmonbekov, Gregory, Brown, \& Xie, 2009).

Moreover, people with a fundamental need to increase social acceptance (high self-monitors) use the material acquisition to help them achieve social acceptance and belongingness (Chan \& Prendergast, 2008). The mission of satisfying the need of self-esteem from materialistic possessions is a cruel cycle that show the way to perpetuating the discrepancy between current and desired states, which in turn guide to little positive feelings about oneself and the incapability to create an ability and esteem about oneself (Kasser et al.'s 2004). These results indicate that peer rejection helps in developing adolescent materialism via lowering implicit self-esteem and that materialism is a way to balance impaired implicit self-esteem (Jiang et al., 2015).We offered the following hypothesis

H2: Self-esteem has a positive impact on materialism.

\subsection{Social Comparisons}

Festinger (1954) provides the social comparisons theory. He suggests that people analyze themselves by comparing with other people usually when the objective mean isn't present. This theory says that comparisons are either face to face or between groups. According to Richins (1991), models in advertisements are a source of comparisons.(Chan, 2013b) say that social comparisons are of two types, upward and downward comparisons. In upward comparison people want to have more and nicer material goods (Chan, 2013a), they compare themselves with other better off people (Chan \& Prendergast, 2007). While in downward comparisons people compare themselves with those who are worse because this can encourage their self-esteem. Communication among adolescents is a way of learning, through communication people know consumption values and what products people like, and this knowledge serve as the basis of social norm that is concerned with consumption values. We hypothesized that,

H3: Social Comparison (SC) has a positive impact on materialism.

\subsection{Communicating With Family and Friends}

Different studies on adolescents in U.S. show that respondents are more materialistic when they less communicate about their consumption with parent (Moore \& Moschis, 1981). A research conducted in Hong Kong on adolescents and young adults has identified that communication with friends on consumption has a positive relation with social comparisons (Chan \& Prendergast, 2008). Communication with peers reflects how much interaction friends have with each other (Lu Wang, Chan, \& Cai, 2009). They said in the same article that people that are young and communicate a lot to peers may 
show a need for peer support in buying material things. A research by Chaplin \& John (2010) showed that, encouraging parents and friends who give emotional support to adolescents improve the self-esteem. Interpersonal insecurity is one of the interesting factors of materialism (Jiang et al., 2015). Insecurity is reduced by Parental and peer support (Chan et al., 2006). Which result in the behavior that adolescents do not have to depend on material things as a way to develop their self-esteem (Chaplin \& John, 2010). An environment of the family that encourages communication and give importance to directing oneself and individual achievement become visible in promoting materialism, whereas a family communication environment that put emphasis on obedience relative to directing oneself show discouragement to the growth of materialism (Grougiou \& Moschis, 2015). So following hypothesis were proposed,

H4a: Communication with parents (CP) has a negative impact on materialism

H4b: Communication with friends (CF) has a positive impact on materialism.

\subsection{The role of advertisement}

Advertising had known itself as a central promotion media and without it, any market cannot carry on (Afzal \& Khan, 2015). The target of international marketers is especially the youth because of their strong purchasing power, size and homogeneity (La Ferle \& Chan, 2008). A study in France found that peer communication and media exposure are the sources of materialism in adolescents (Benmoyal-Bouzaglo \& Moschis, 2010). Kasser et al., (2004) model explain that media, culture, and advertisements are the source of materialistic values, those people who are open to the elements of materialistic models are found more materialistic than those who are not (Bandura, 1971). Likewise, television is a main and leading resource of entertainment in Pakistan (Ahmad et al., 2013). Children in different countries spend almost 3-4 hours/day in watching T.V (Hassan \& Daniyal, 2013). Even in a developing country like Pakistan, 55\% household had a television in 2007 (Khan, 2013). In a report published by The State of Electronic Media in Pakistan (2010), it was said that Pakistan television (PTV) was the first television channel that goes on air in 1964. And Today 81 local Channels and 50 foreign channels are being aired. Most of these channels provide 24 hours nonstop entertainment. Children below 12 age liked to look at child dramas, cartoons and child games (Lu Wang et al., 2009). Whereas, adolescents show extra attention to news programs and sports programs (Khan, 2013). Adolescents watch television mostly for the attainment of companionship and for listening to the news (Bindah \& Othman, 2011).Different researchers find that exposure to media control materialism in adolescents between 15-19 year of ages in China (Gu \& Hung, 2009). While in young adults between 18-32 year of age in US and French (Moschis et al., 2013). On the bases of study following hypothesis were offered,

H5: Attention to television (AT) has a positive impact on materialism.

H5a: Time spent on Pakistani (TV) channels has a positive impact on materialism.

H5b: Time spent on Foreign (TF) channels has a positive impact on materialism.

H5c: Time spent on Newspaper (TN) has a positive impact on materialism.

H5d: Time spent on the internet (TI) has a positive impact on materialism.

\subsection{Conceptual Framework}

The study has adopted the conceptual framework from two earlier studies. One is John (1999) model of consumer socialization of children and second is Kasser et al.'s (2004) model of materialistic value orientation. According to John (1999) model young people have different spending motives and have different values in different ages. Conferring to the second model, feeling of insecurity are induced in consumers through experience and form exposure to materialistic model and values that results in the development of materialistic value. When an individual psychological desires are not fulfill then, to reduce the stressful effects of insecurity, they adopt materialism as an alternate or compensatory strategy.

The active mental processing of incoming messages are measured by social comparison's and attention to TV advertising (Chan, 2013a). So, in this study we replaced two variables feeling of insecurity and materialistic models by social comparisons and attention to TV advertisement. Conceptual framework is shown in figure 1 below. 


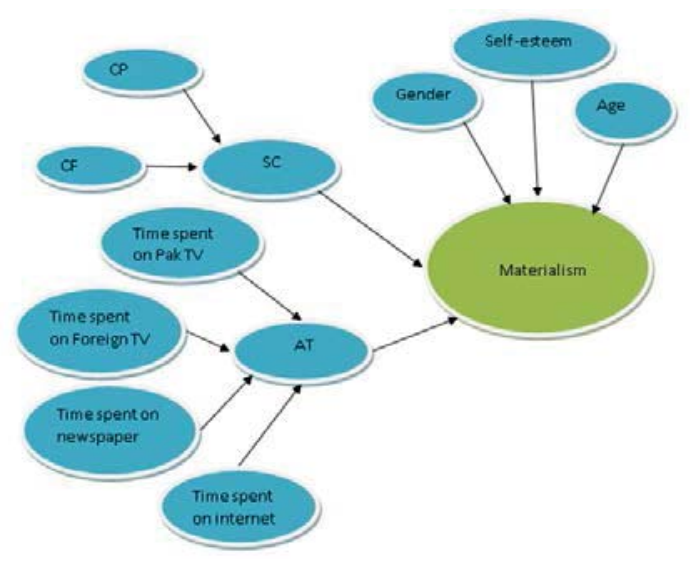

Figure 1: Conceptual framework

\subsection{Television viewership in Pakistan}

Television is considered as the strongest mode of advertisement, because of its heap reach, it not only has the power to change personal attitude, behavior, lifestyle, but also the culture of the country (Abideen \& Salaria, 2009). Advertising had known itself as a central promotion media and without it, any market cannot carry on (Afzal \& Khan, 2015). The target of international marketers is especially the youth because of their strong purchasing power, size and homogeneity (La Ferle \& Chan, 2008).

Youth is more liable to pass changes in their behavior, and same holds true for Pakistani youth (Jabbar, Yasin, Ahmed, \& Umair, 2014). This study is conducted to know that how Pakistani adolescents support new materialistic value's. WHO identifies adolescence as the" era in human growth and development that take place after childhood and before adulthood, from ages 10 to19" (World Health Organization, 2012). It is estimated that 60 percent of Pakistani population consist of children and teenagers (Population Association of Pakistan, 2014). Out of 169 million total population of Pakistan, nearly 30 million consists of adolescents 10 to 19-year-old (Kashif et al., 2012). Children of different countries spend almost 3-4 hours/day in watching T.V (Hassan \& Daniyal, 2013). Even in a developing country like Pakistan, 55\% household had a television in 2007 (Khan, 2013). Television advertisements are important in the expansion of business, particularly in marketing (Hassan \& Daniyal, 2013). In a report published by The State of Electronic Media of Pakistan (2014),it is said that Pakistan television (PTV) was the first television channel that goes on air in 1964. And Today 81 local Channels and 50 foreign channels are being aired. Most of these channels provide 24 hours nonstop entertainment. Children below 12 age liked to look at child dramas, cartoons and child games (Chan et al., 2006). Whereas, adolescents show extra attention to news programs and sports programs (Khan, 2013). Adolescents watch television mostly for the attainment of companionship and for listening to the news (Bindah \& Othman, 2011).

\section{Methodology}

\subsection{Research Design}

The present study incorporated Trinh, (2012) materialism scale, to measure materialism in adolescents of Pakistan. This scale consist of 16 items which measures four materialism component i.e., success, happiness, essentiality, and distinctiveness. To follow the change in materialism and other variables by age a sample survey was conducted. The survey was conducted during the period of May to June 2015.We chose students as respondents of the study For the purpose of data analysis, we took adolescents of age 14 to 22 years. For our convenience in data analysis, we have divided ages into three groups, 14-16 years, 17-19 years and 20-22 years. We choose this age range for our study because they are more likely to be aware of their opinions and more likely to completely understand the questionnaire. School types were quite different so instead of sticking to the ages we decided to choose school college and university students as respondents of our study. According to the education system of Pakistan we selected grades nine and ten, 
leading to Secondary school, grades eleven and twelve, leading to higher secondary school and university programs leading to undergraduate degree programs.

\subsection{Sampling}

Systematic random sampling technique was used in this research to collect data from 285 students, where adolescents and young adults study. There is $5 \%$ probability of error in data collection. A list of the university in the region is downloaded from official website of HEC. However, for schools, only those schools were selected that gives both secondary and higher secondary education. According to Board of Intermediate and Secondary Education (2015) there are 216 private school and colleges in Abbottabad, and one thousand private schools in Islamabad (Private Educational Institutions Regulatory Authority, 2015). There are total three universities in Abbottabad and fourteen universities in Islamabad (Higher Education commission, 2015). A systematic random sampling of four school and two universities is selected. The researcher contacted the school's principal and invited them for participation in the study. The schools that refused to participate were replaced by another school included in the list. The questionnaire along with the cover letter that specify the purpose of research where given to the sampled schools. The sampled schools were requested to distribute the questionnaire randomly to each class from 9 class to 12 class. While in the case of the university, students were approach directly to collect data from them. Altogether ten schools and three universities participated in the survey.

\subsection{Participants}

Altogether 300 completed questionnaires were collected. Fifteen respondents above aged twenty-two were disqualified as they were considered as out of the scope of study. The final sample size was 285. The mean age of the sample was 18.11.Table 1 summarizes the sample profile in terms of gender, age, place, school grade, the level of family income, and receiving regular allowances from family or not. Nearly an almost equal distribution of gender is in the sample profile. There was a total of 38 percent of secondary school students, 32 percent of undergraduate and 31 percent of higher secondary school students of the sample profile. Out of total respondents, 52 percent's of the respondents belongs to Abbottabad and the rest from Islamabad. Most of the students (84 percent) gets regular income from their family and only 16 percent did not get regular allowances.10 percent of the participants of the study think that their family income is low, 20 percent think that it is high than other families in the city. and most of them (70 percent) do not know whether family income is higher or lower in comparison to other families in the city.

Table 1. Sample Profile

\begin{tabular}{|c|c|c|}
\hline & Frequency & $\%$ \\
\hline \multicolumn{3}{|l|}{ Sex } \\
\hline Female & 117 & 41 \\
\hline Male & 167 & 59 \\
\hline \multicolumn{3}{|l|}{ Age } \\
\hline 14 & 19 & 7 \\
\hline 15 & 71 & 25 \\
\hline 16 & 26 & 9 \\
\hline 17 & 5 & 2 \\
\hline 18 & 17 & 6 \\
\hline 19 & 37 & 13 \\
\hline 20 & 25 & 9 \\
\hline 21 & 45 & 16 \\
\hline 22 & 39 & 14 \\
\hline \multicolumn{3}{|l|}{ Place } \\
\hline Abbottabad & 148 & 52 \\
\hline Islamabad & 136 & 48 \\
\hline \multicolumn{3}{|l|}{ School Grade } \\
\hline Secondary school (grade 9) & 24 & 9 \\
\hline (grade 10) & 83 & 29 \\
\hline Higher secondary (grade 11) & 60 & 21 \\
\hline
\end{tabular}




\begin{tabular}{|l|c|c|}
\hline (grade 12) & 26 & 10 \\
\hline Under grade & 91 & 32 \\
\hline Family Income & & \\
\hline less & 27 & 10 \\
\hline More & 58 & 20 \\
\hline Do not Know & 199 & 70 \\
\hline Receiving Regular allowance from family & & \\
\hline Yes & 239 & 84 \\
\hline No & 47 & 16 \\
\hline Note: $(\mathrm{N}=285)$ & & \\
\hline
\end{tabular}

\subsection{Procedure}

In schools, the questionnaire were distributed during the normal class session and teachers of the class helped in collecting the completed questionnaire from the students. The questionnaire was self-administered by the students, and their participation was voluntary. No incentives were given to the students for filling these questionnaires and neither incentive to school. The principal of the school vetted the questionnaire and made a decision in participating in the study. These questions were picked up by the researcher. In the case of university students, the questionnaire were distributed personally during the class session and voluntary students fill the questionnaire and return that back to the researcher.

\subsection{Measures of materialism}

The constructs used in this study have been used before in similar studies and have established reliabilities. Materialism is measured by using sixteen-item materialism scale of Trinh and Phau, 2012. Participants were requested to mark these statements on 5-point scale 1=disagree very much, $5=$ =agree very much. Cronbach alpha was 0.83 .

Moschis \& Moore (1982) scale was used to measure communication with parents and friends. Total Six statements were measured on five-point Lickert scale (1=Never, $5=$ Nearly Ever). Cronbach alpha was 0.70 .

Chan \& Prendergast (2008) scale of SC were used by asking respondents what their friends richer to them buy, on five-point Lickert scale (1=Never, 5=Nearly Ever). Cronbach alpha, in this case, was 0.70 .

AT was measured by asking respondents to rate one item on five-point Licker scale (1=Never, 5=Nearly Ever).

Rosenberg self-esteem scale (short version) was used to measure self-esteem (Blascovich \& Tomaka, 1991).

Respondents were asked to rate four statements on five-point Licker Scale (1=disagree very much, 5=agree very much). The Cronbach alpha, in this case, was 0.84 .

\section{Research Findings}

The mean of four media including Pakistani TV channels, foreign TV channels, internet and newspaper were 2.15, 2.06, 1.8 and 2.9 respectively. This means that respondents spend more time on the internet than in watching Pakistani TV channels and then foreign TV channels respectively. They spend less time in reading the newspaper. On average respondents spend 2 hours/day in watching television. Communication with friends was positively skewed (skewness = 0.658 ) whereas communication with parents was negatively skewed (skewness $=-0.056$ ). The means of communication with friends and communication with parents about the social comparison of consumption were 6.44 (s.d. = 1.96) and 3.04 (s.d. $=0.98$ ) respectively. Adolescents in urban Pakistan communicate about their consumptions more frequently with friends than with parents. One of the variables related with the advertisement was attention given by the respondents to the advertisement. It reported that people rarely give attention to the advertisement.

\subsection{Materialism and age}

The ANOVA results were significant. $\mathrm{F}(2,281)=12.50, \mathrm{P}<0.05$. Consequently, there is a significant evidence to conclude that there is a significant difference in materialism scores of the three age groups. Post-Hoc tests were done to evaluate pairwise comparisons among group's means with the help of Tukey HSD test since equal variances were tenable. The test revealed the significant pairwise difference between young adult and adolescents. As age increases materialism decreases, so our H1 is supported. Materialism scores of students of age group (20-22) years were significantly low. So H1a; Young adults are less materialistic as compared to adolescent was also supported. The graph 
above explains the results more clearly. Our result suggests that Materialism scores decrease heavily from age 1(14-16) to age group 2 (17-19).And then from age group 2(17-19) to age group 3(20-22) decrease is slow.

\subsection{Correlation}

Table 2 below shows the correlation matrix of all the variables involved in regression analysis. Results show that materialistic value orientation of respondents was positively related with communication with friends, time spent on watching foreign TV, time spent on newspaper, social comparison of consumption with friends, attention to TV advertising. Materialism has an inverse relationship with age and communication with parents.

The highest correlation was found between time spent on reading newspaper and time spent on foreign TV $(r=$ 0.29). second highest correlation was between time spent on internet and time spent on watching foreign $\operatorname{TV}(r=$ 0.25).Communication with friends and communication with parents had a positive correlation $(r=0.21)$ and it was same as in correlation between the social comparison of consumption with friends and time spent on the internet $(r=0.21)$. The third highest correlation was found between time spent on internet and time spent in reading the newspaper $(r=0.22)$.

Table 2. Correlation Matrix

\begin{tabular}{|c|c|c|c|c|c|c|c|c|c|c|c|c|}
\hline & 1 & 2 & 3 & 4 & 5 & 6 & 7 & 8 & 9 & 10 & 11 & 12 \\
\hline 1. Materialism & 1 & & & & & & & & & & & \\
\hline 2. $\mathrm{CP}$ & -.083 & 1 & & & & & & & & & & \\
\hline 3. $\mathrm{CF}$ & .036 & $.210^{*+}$ & 1 & & & & & & & . & & \\
\hline 4. TV & -.057 & .072 & -.009 & 1 & & & & & & & & \\
\hline 5. TF & .088 & .002 & .034 & $.179^{+*}$ & 1 & & & & & & & \\
\hline 6. TN & .032 & -.046 & -.061 & $.125^{*}$ & $.290^{*+}$ & 1 & & & & & & \\
\hline 7. $\mathrm{TI}$ & -.040 & $.196^{\star \star}$ & $.193^{*+}$ & .014 & $.255^{*+}$ & $.223^{*+}$ & 1 & & & & & \\
\hline 8. $\mathrm{SC}$ & $.171^{* *}$ & $.167^{* \star}$ & $.221^{*}$ & $.181^{*+}$ & .074 & $.173^{+*}$ & $.211^{*+}$ & 1 & & & & \\
\hline 9. AT & .093 & -.064 & .045 & .012 & $-.118^{*}$ & -.020 & .022 & -.062 & 1 & & & \\
\hline 10. Self-esteem & -.081 & -.044 & .008 & -.077 & -.060 & $-.144^{*}$ & $-.133^{*}$ & $-.175^{*+}$ & .012 & 1 & & \\
\hline 11. Age & $-.269^{*+}$ & $.224^{* *}$ & .074 & .054 & -.037 & .034 & $.276^{*+1}$ & $.172^{+*}$ & -.041 & $-.135^{*}$ & 1 & \\
\hline 12. Gender $(1=\mathrm{M}, 2=\mathrm{F})$ & .037 & -.021 & -.061 & .080 & -.050 & -092 & $-.219^{* *}$ & -.062 & -.029 & .099 & $-.337^{+*}$ & 1 \\
\hline
\end{tabular}

Note: ${ }^{* \star}$. Correlation is significant at the 0.01 level (2-tailed).

*. Correlation is significant at the 0.05 level (2-tailed).

SC was predicted by CP and CF. While AT was predicted by time TV, TF, TN and TI. In order to predict materialism scores of respondents, four steps were conducted in the regression model. In the first step age range and gender were included, Social comparison of consumption with (SC) was added in the second step. In third step Attention to TV advertising (AT) was added and lastly, in fourth step self -esteem was added.

Table 3: Simple regression for SC

\begin{tabular}{|l|c|c|c|}
\hline Predictors & Beta & t-value & Sig \\
\hline \hline CP & $.126^{\star}$ & 2.13 & .034 \\
\hline \hline CF & $.194^{\star *}$ & 3.29 & .001 \\
\hline \hline R-square & & .064 & \\
R-square Change & & .064 & \\
F-value & & $9.60^{\star *}$ & \\
\hline
\end{tabular}

Note: Dependent variable: $\mathrm{SC},{ }^{*} \mathrm{P}<0.05,{ }^{* *} \mathrm{P}<0.001$

SC accounted for 6.4 percent of variance and it was predicted by CP and CF. CP related positively (standardized beta 
$=0.12$ at $0.034 \%$ level of significance) while CF also related positively (standardized beta $=0.19$ at 0.001 percent level of significance). So, hypothesis $\mathrm{H} 2 \mathrm{a}$ and $\mathrm{H} 2 \mathrm{~b}$ are supported. This means that respondents in Pakistan communicate about their consumptions more frequently with friends as compared to parents. Table 3 above show the results for SC.

Media consumption was used to foresee AT. All the four variables including time spent on Pakistani TV, foreign $\mathrm{TV}$, and time spent in reading newspaper, time spent on the internet accounted for only 9 percent of the variance. Time spend on watching Pakistani TV, foreign TV and on the internet was significant. Therefore, hypothesis $\mathrm{H} 3 \mathrm{a}, \mathrm{H} 3 \mathrm{~b}$, and $\mathrm{H} 3 \mathrm{~d}$ are supported. Time spent on Pakistani TV channels and on internet related positively while time spent on foreign TV channels was negatively related. Time spent on the newspaper was not a significant predictor. Hence, hypothesis H3c was not supported. Time spent on watching Pakistani TV channels was related positively (standardized beta $=0.20, \mathrm{P}<$ 0.05). This means that time spent on Pakistani TV channels will affect positively towards consumers AT. Time spent on internet (standardized beta $=0.16, \mathrm{P}<0.05$ ). This means that time spent on the internet will also affect positively towards consumers AT. The time spent on watching foreign TV (standardized beta $=-0.12, P<0.05$ ). This means that the time spent on foreign TV channels will affect adversely towards consumers AT. And the time spent on reading newspaper (standardized beta $=0.16, \mathrm{P}>0.05$ ) was not significant. Table 4 below show the results for AT.

Table 4: Simple regression for AT

\begin{tabular}{|c|c|c|c|}
\hline \multicolumn{1}{|c|}{ Predictors } & Beta & t-value & Sig \\
\hline \hline TV & $.205^{\star \star}$ & 3.58 & .00 \\
\hline TF & $-.129^{\star}$ & -2.26 & .024 \\
\hline TN & -.018 & -.316 & .752 \\
\hline TI & $.166^{*}$ & 2.895 & .004 \\
\hline \hline $\begin{array}{l}\text { R-square } \\
\text { R-square change } \\
\text { F-value }\end{array}$ & & .09 & \\
\hline
\end{tabular}

Note: Dependent Variable: $S C,{ }^{*} \mathrm{P}<0.05,{ }^{* *} \mathrm{p}<0.001$

\subsection{Multiple Regression Analysis:}

A theoretical model was examined by using multiple regression analysis. Table 5 below illustrate the results of multiple regression. A stepwise multiple regression was run to evaluate whether age, gender, self-esteem, SC and AT scores were necessary to predict materialism scores in adolescents. Multiple Regression analysis was run in four steps. Table 5 below show the results of multiple regression analysis in detail. At step 1 age and gender were entered as an independent variable in regression equation $\mathrm{F}(2,281)=11.48, p<0.05$. The multiple correlation coefficient was 0.076 , indicating approximately 7.6 percent of the total variance of materialistic scores $(t=-4.74, p<.05)$. Gender was not significant predictor while age was a significant predictor. Materialism scores decrease by 0.28 percent with every one unit increase in age. So young adults are less materialistic than adolescents. In the second step when Social comparison of consumption with friend was entered in regression equation to predict materialism. $F(3,280)=13.20, p<0.05$ and it accounted for 12.4 percent of total variation as multiple correlation coefficient was 0.124 , $(t=3.93, p<0.05)$. When age and Gender are controlled, SCCWF was related positively to materialism. Therefore H2: Social comparison of consumption with friends has a positive impact on materialism was supported. Results show that respondents who communicate about consumptions with friends and parents encourage social comparison of consumption. In the third step of regression when AT was added, $R$ square change is 0.00 . It means that AT was not related with materialism. As a result H3: AT has a positive impact on materialism was not supported. In the last step when self-esteem was added, Rsquare was 13 percent (standard beta $=-0.08, P>0.05$ ). Hence, self-esteem was also not related with materialism. Thus, H4: Self-esteem has a negative impact on materialism was also not supported. Which means that as the age of respondents increased, materialism scores decrease in respondents. SC was also related with materialism. All the five Variables together accounted for 13 percent of the variance in materialistic scores. 
Table 5. Multiple regression analysis summary of materialism scores

\begin{tabular}{|c|c|c|c|c|c|c|c|c|}
\hline \multirow[b]{2}{*}{ Step/predictors } & \multicolumn{2}{|c|}{ Step 1} & \multicolumn{2}{|c|}{ Step 2} & \multicolumn{2}{|c|}{ Step3 } & \multicolumn{2}{|c|}{ Step 4} \\
\hline & Beta & $\mathrm{t}$ & Beta & $t$ & Beta & $\mathrm{t}$ & Beta & t \\
\hline $\begin{array}{l}\text { Age } \\
\text { Gender(0=male,1= female) } \\
\text { SCCWF } \\
\text { ATAD } \\
\text { Self-esteem }\end{array}$ & $\begin{array}{l}-.28^{\star \star} \\
-.06\end{array}$ & $\begin{array}{l}-4.74 \\
-.98\end{array}$ & $\begin{array}{l}-.32^{\star \star} \\
-.05 \\
.22^{\star \star}\end{array}$ & $\begin{array}{l}-5.43 \\
-.99 \\
3.93\end{array}$ & $\begin{array}{c}-.32^{\star \star} \\
-.05 \\
0.22^{\star \star} \\
0.09\end{array}$ & $\begin{array}{l}-5.37 \\
-.91 \\
4.03 \\
1.65\end{array}$ & $\begin{array}{l}-0.33^{\star \star} \\
-0.04 \\
0.21^{\star *} \\
0.09 \\
-0.08\end{array}$ & $\begin{array}{r}-5.49 \\
-0.83 \\
3.76 \\
1.65 \\
-1.48\end{array}$ \\
\hline $\begin{array}{l}\text { R-square } \\
\text { R-square change } \\
\text { F value }\end{array}$ & \multicolumn{2}{|c|}{$\begin{array}{c}0.076 \\
0.076 \\
11.48^{\star \star}\end{array}$} & \multicolumn{2}{|c|}{$\begin{array}{c}0.124 \\
0.048 \\
13.20^{\star *}\end{array}$} & \multicolumn{2}{|c|}{$\begin{array}{c}0.132 \\
0.008 \\
10.64^{\star *}\end{array}$} & \multicolumn{2}{|c|}{$\begin{array}{l}0.139 \\
0.007 \\
8.99 * \star\end{array}$} \\
\hline
\end{tabular}

Note: ${ }^{\star} \mathrm{p}<0.05,{ }^{* \star} \mathrm{p}<0.001$

\subsection{Results of Path Analysis}

According to (Newsom, 2012) total effect of a path is calculated by multiplying corresponding standardized beta coefficient's together. The results of the paths can be seen clearly in Figure 2 below. Our findings show that the path with the largest total effect was the inverse relation of age on materialism (i.e. -0.33). The path with second highest total effect was of CF by SC $\left(0.03=0.19^{*} 0.21\right)$. The figure was arrived by taking the product of the standardized beta coefficient of communication with friends and social comparison of consumption with friends (i.e. 0.19) and the standardized beta coefficient of social comparison of consumption with friends and materialism (i.e. 0.21).Materialism scores were higher in older respondents than younger respondents. This means that respondent's materialism scores decrease as age increases. Younger respondents of Pakistan are more materialistic. The materialism scores were also higher for those respondents who communicate frequently on consumption with friends and those who frequently engage in a social comparison of consumption with friends.

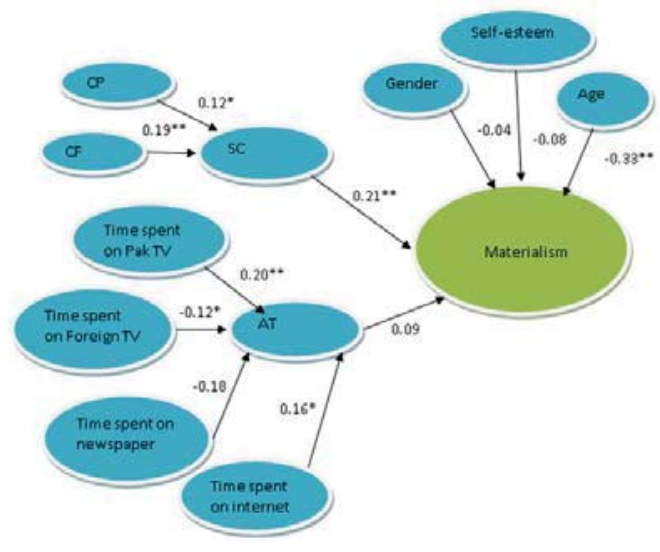

Figure 2: Path diagram

\section{Discussion \& Implication}

In the present study, we envisage that SC is influenced by interpersonal communication of respondents and AT is influenced by media communication. And these two variables i.e., SC and AT, in turn, control materialism. Our calculations indicate that CF had a strong and positive relation as compared to CP. Parents as opinion leader can also take on a social comparison of consumption (Chan, 2013a). A research by Fitzmaurice \& Comegys (2006) specifies that opinion leaders frequently convey materialistic values by supporting other people to consume products. It can be perceived that in Pakistan the existence of all interpersonal communication factors on a social comparison of 
consumption on adolescents and young adults indicate that social comparison of consumption may be a fact that is vigorously rooted in Pakistani culture. And therefore, all types of interpersonal communication will support comparison behavior (Chan, 2013b).

In the present study, support of materialistic values was found to decrease with age. Pakistani adolescents were found to be more materialistic than young adults. Our results are in line with (Chaplin \& John, 2007) study. Another study on adolescents in Singapore by La Ferle \& Chan (2008) also found that materialistic values decrease with age.

In our results although communication with parents was positively correlated with SC, but it was more positively correlated with communication with friends. The level at which respondents communicate with peer shows the level of peer interaction(Chan, 2013a). The reason may be that the topic of most discussion between friends (respondents) is mostly about brands and possessions. This also shows that those adolescents and young adults who regularly communicate about their consumptions have more knowledge about products that are latest in the market, latest advertisements, and the latest trends in the market. And mostly these respondents do more social comparisons of consumption. Sharing of this consumption knowledge about friends indicates that respondents are eagerly interested in knowing that, whether their friends are using latest or same brands as they are using or not?

Time spent on Pakistani TV channels, foreign TV channels and on the internet had a positive correlation with AT. While time spent on reading newspaper had no positive Correlation with AT. The reason may be that all types of advertisements were not measured in this research only attention to advertising was measured. We can say that respondents who spent more time in watching Pakistani TV channels and on the internet give more attention to advertising. Previously most of the researchers finds a positive relationship linking materialism and TV AT exposure (Buijzen \& Valkenburg, 2003; Lu Wang et al., 2009; Moschis \& Moore, 1982) generally AT exposure (Chia, 2010).

Gender had no influence on materialism but age had an inverse relationship with materialism. In the present study, young adults were less materialistic. The reason may be that young adults have more consumption and possession experience. So they may have realized the fact that being happy doesn't mean owning more things. The second explanation may that at this age adults have understood that ownership goes beyond material essentiality and material distinctiveness. They think that personal success and happiness in life could be attaining without acquiring essentiality and distinctiveness in life. Therefore, we can say that adults have a value of ownership that goes beyond being distinct or unique or having essential possessions in life. The third explanation to this can be as materialism is considered as a negative trait of life and young adults are more aware of this. So it is possible that they give socially desirable answers.

SC had a positive influence on materialistic values. Our results are in line with (Chan \& Prendergast, 2007; Chan, 2013a). Respondents who communicate more about their consumption with friends believe that more money and essential possessions' will make them distinct in life and this will, in turn, lead to personal success and happiness in life. We can also interpret from this that those people who give importance to material things are the one who are engaged in social comparisons. As only upward social comparisons are studied in the present study. Hence, we say that upward social comparisons support materialistic values in individuals.

AT had no influence on materialism. Our findings are in line with earlier studies (Buijzen \& Valkenburg, 2003; Chan, 2013a, 2013b). This indicate that paying more attention to TV advertising does not support materialistic values in adolescents and young adults. In our research, we didn't include the variables like, motivation to watch advertisements and positive attitude of advertisements. This could be the possible reason of limited or no influence of advertisement on materialism. The two variables, motivation to view advertising and positive attitude of advertising measures an active form of advertising and moderate form of advertising. This will, in turn, measure a high level of commitment with advertising and mental processing of advertising message. So, further research should be conducted by including these variables.

Overall the study provides an insight into the empirical investigation of growing materialism among young consumers in Pakistan. It validates and supports John (1999) and Kasser et al.'s (2004) models in Pakistani settings. Age and communication with friends is found to positive associated with consumes materialistic values. Interpersonal influence established a stronger effect in calculating materialism among consumers as compared to their attention to advertisements. However, media influence was not stronger as compared to the influence of interpersonal influence. The results are support by earlier study conducted by Shah \& Amjad (2011) and Shah (2013) where a strong collectivist culture of the country is examined and acknowledged.

\subsection{Limitations}

The results of our research show that attention to TV advertising alone are not enough to find materialistic value orientation. Other variables like, motivation to view advertising and positive attitude towards advertising should also be included. Further research is required in this context. Also because of limited time period the sample of only college and 
university students as adolescents and young adults was taken, so further research should be done by taking professional and married young adults i.e., (who recently entered in practical life )to compare materialistic value orientation within them.

\subsection{Research contribution}

Our research contributes to the body of literature by enhancing theoretical understanding of consumer willingness of consumptions through social comparisons, attention to TV advertising and its influence on materialism in the context of Pakistan. It shows empirical evidence that consumer attitudes and behavioral responses towards willingness of consumption are significantly varied by material values (material success, material happiness, material essentiality and material distinctiveness). The study is among the pioneered studies examining antecedents of materialism in Pakistan.

\section{References}

Abideen, Z. U., \& Salaria, R. M. (2009). Effect of television advertising on children:with special reference to pakistani urban children. Munich Personal RePEc Archive(MPRA), (22321).

Achenreiner, G. B. (1997). Materialistic values and susceptibility to influence in children. Advances in Consumer Research, 24, 82-88.

Afzal, S., \& Khan, J. R. (2015). Impact of Online and Conventional Advertisement on Consumer Buying Behaviour of Branded Garments, 4(January), 125-135.

Albert Lange, F. (1925). The history of materialism, by frederick albert lange. Kegan paul, trench, trubner.

Baker, S. M., \& Gentry, J. W. (1996). Kids as collectors: a phenomenological study of first and fifth graders. Advances in Consumer Research, 23, 132-137.

Bandura, A. (1971). Social learning theory. In Social Learning Theory (pp. 1-46).

Belk, R. (1985). Materialism: Trait aspects of living in the material world. Journal of Consumer Research, 265-280.

Benmoyal-Bouzaglo, S., \& Moschis, G. P. (2010). Effects of family structure and socialization on materialism: a life course study in France. Journal of Marketing Theory and Practice, 18(1), 53-70.

Beutel, A. M., \& Marini, M. M. (1995). Gender and values. American Sociological Review, 436-448.

Bindah, E. V., \& Othman, N. (2011). The role of family communication and television viewing in the development of materialistic values among young adults . A review . International Journal of Business and Social Science, 2(23), 238-248.

Blascovich, J., \& Tomaka, J. (1991). Measures of self-esteem. Measures of Personality and Social Psychological Attitudes, 1, 115-160.

Board of Intermediate and Secondary Education (BISE). (2015). List of Schools in Abbottabad. Abbottabad.

Buijzen, M., \& Valkenburg, P. M. (2003). The Unintended Effects of Television Advertising: A Parent-Child Survey. Communication Research.

Bush, A. J., Martin, C. A., \& Clark, P. W. (2001). The effect of role model influence on adolescents' materialism and marketplace knowledge. Journal of Marketing Theory and Practice, 27-36.

Chan, K. (2013a). Development of materialistic values among children and adolescents. Young Consumers, 4.

Chan, K. (2013b). Materialism among Chinese children in Hong Kong. Young Consumers.

Chan, K., \& Prendergast, G. (2007). Materialism and Social Comparison Among Adolescents. Social Behavior and Personality: An International Journal, 35(2), 213-228. doi:10.2224/sbp.2007.35.2.213

Chan, K., \& Prendergast, G. P. (2008). Social comparison, imitation of celebrity models and materialism among Chinese youth. International Journal of Advertising, 27(5), 799-826.

Chan, K., Zhang, H., \& Wang, I. C. (2006). Materialism among adolescents in urban China. Young Consumers, 7(2), 64-77.

Chaplin, L. N., \& John, D. R. (2007). Growing up in a material world: Age differences in materialism in children and adolescents. Journal of Consumer Research, 34(4), 480-493.

Chaplin, L. N., \& John, D. R. (2010). Interpersonal influences on adolescent materialism: A new look at the role of parents and peers. Journal of Consumer Psychology, 20(2), 176-184. doi:10.1016/j.jcps.2010.02.002

Chia, S. C. (2010). How social influence mediates media effects on adolescents' materialism. Communication Research.

Churchill, Jr., G. A., \& Moschis, G. P. (1979). Television and Interpersonal Influences on Adolescent Consumer Learning. Journal of Consumer Research.

Churchill, G. A., \& Moschis, G. P. (1979). Television and interpersonal influences on adolescent consumer learning. Journal of Consumer Research, 23-35.

Easterlin, R. A., \& Crimmins, E. M. (1991). Private materialism, personal self-fulfillment, family life, and public interest THE nature, effects, and causes of recent changes in the values of American youth. Public Opinion Quarterly, 55(4), 499-533.

Ferle, C. La, \& Chan, K. (2008). Determinants for materialism among adolescents in Singapore. Young Consumers: Insight and Ideas for Responsible Marketers. doi:10.1108/17473610810901633

Festinger, L. (1954). A theory of social comparison processes. Human Relations, 7(2), 117-140.

Fitzmaurice, J., \& Comegys, C. (2006). Materialism and social consumption. Journal of Marketing Theory and Practice, 14(4), 287-299.

Flurry, L. A., \& Swimberghe, K. (2016). Consumer Ethics of Adolescents. Journal of Marketing Theory and Practice, 24(1), 91-108. doi:10.1080/10696679.2016.1089766 
Fournier, S., \& Richins, M. L. (1991). Some theoretical and popular notions concerning materialism. Journal of Social Behavior \& Personality.

Goldberg, M. E., Gorn, G. J., Peracchio, L. A., \& Bamossy, G. (2003). Understanding Materialism Among Youth. Journal of Consumer Psychology.

Grougiou, V., \& Moschis, G. P. (2015). Antecedents of young adults' materialistic values. Journal of Consumer Behaviour, 14(2), 115126.

Gu, F. F., \& Hung, K. (2009). Materialism among adolescents in China: a historical generation perspective. Journal of Asia Business Studies, 3(2), 56-64.

Hassan, A., \& Daniyal, M. (2013). Impact of Television Programs and Advertisements on School Going Adolescents : a Case Study of Bahawalpur City, Pakistan, 7(1), 26-37.

Higher Education commision, P. (2015). HEC Recognized Universities and Degree Awarding Institutions.

Jabbar, S., Yasin, G., Ahmed, U., \& Umair, A. (2014). Transformation of Value System Due to International Integration. A Sociological Analysis Conducted at University of Sargodha. Mediterranean Journal of Social Sciences, 5(16), 552-560. doi:10.5901/ mjss.2014.v5n16p552

Jiang, J., Zhang, Y., Ke, Y., Hawk, S. T., \& Qiu, H. (2015). Journal of Experimental Social Psychology Can ' t buy me friendship ? Peer rejection and adolescent materialism : Implicit self-esteem as a mediator. Journal of Experimental Social Psychology, 58, 48-55. doi:10.1016/j.jesp.2015.01.001

John, D. R. (1999). Consumer Socialization of Children: A Retrospective Look At Twenty-Five Years of Research. Journal of Consumer Research.

Kashif, M., Altaf, U., Ali, S., Asif, U., Ayub, H. M., Abeer, W., \& De Run, E. C. (2012). Pakistani childrens' views of tv advertising. Trziste, 24(2), 245-261.

Kasser. (2002). The High Price of Materialism. Academy of Management Review. doi:10.5465/amr.2004.11851766

Kasser, Ryan, Couchman, \& Sheldon. (2004). Materialistic values: Their causes and consequences. Psychology and Consumer Culture, American Psycology Association, Washington DC., (July), 11-28. doi:10.1037/10658-002

Kasser, T. (2008). Pain and insecurity, love and money. Psychological Inquiry, 19(3-4), 174-178.

Kasser, T. I. M., Ryan, R. M., Couchman, C. E., \& Sheldon, K. M. (2004). Materialistic values: their causes and consequences. Psychology and Consumer Culture The Struggle for a Good Life in a Materialistic World, 11.

Khan, M. A. (2013). Television Viewing and Schoolgirls of Multan: A Uses and Gratifications Approach. Pakistan Journal of Social Science(PJSS), 33(2), 297-310.

Korten, D. C. (1999). The post-corporate world: Life after capitalism. Berrett-Koehler Publishers.

La Ferle, C., \& Chan, K. (2008). Determinants for materialism among adolescents in Singapore. Young Consumers, 9(3), $201-214$.

Lu Wang, C., Chan, K., \& Cai, X. (2009). Influence of television advertising on adolescents in China: an urban-rural comparison. Young Consumers, 10(2), 133-145.

Moore, R. L., \& Moschis, G. P. (1981). The role of family communication in consumer learning. Journal of Communication, 31(4), 42-51.

Moschis, G. P., \& Churchill, G. A. (1978). Consumer socialization: A theoretical and empirical analysis. Journal of Marketing Research, 15(4), 599-609.

Moschis, G. P., \& Moore, R. L. (1982). A Longitudinal Study of Television Advertising Effects. Journal of Consumer Research. doi:10.1086/208923

Moschis, G. P., State, G., Mathur, A., Fatt, C. K., Lumpur, K., \& Pizzutti, C. (2013). Effects of Family Structure on Materialism and Compulsive Consumption : A Life Course Study in Brazil. Journal of Research for Consumers(jrc), 66-96.

Newsom. (2012). Testing Mediation with Regression Analysis.

Osmonbekov, T., Gregory, B. T., Brown, W., \& Xie, F. T. (2009). How consumer expertise moderates the relationship between materialism and attitude toward advertising. Journal of Targeting, Measurement and Analysis for Marketing, 17(4), 321-327. doi:10.1057/jt.2009.23

Population Association of Pakistan. (2014). Annual report.

Private Educational Institutions Regulatory Authority, P. (2015). List of Schools in Islamabad.

Richins, M. L. (1987). Media, materialism, and human happiness. Advances in Consumer Research, 14(1), 352-356.

Richins, M. L. (1994). Special possessions and the expression of material values. Journal of Consumer Research, 522-533.

Richins, M. L., \& Dawson, S. (1992). A Consumer Values Orientation for Materialism and Its Measurement: Scale Development and Validation. Journal of Consumer Research, 19(3), 303. doi:10.1086/209304

Shah, S. A. M. (2013). Managing Internationalization Strategy with Cultural Realities: Guidelines for Higher Education Institutes in Pakistan. World Applied Sciences Journal, 25(11), 1542-1548. doi:10.5829/idosi.wasj.2013.25.11.1508

Shah, S. A. M., \& Amjad, S. (2011). Cultural Diversity in Pakistan: National vs Provincial. Mediterranean Journal of Social Sciences, 2(2), 331-344.

The State of Electronic Media of Pakistan. (2014). Annual Report.

Viet Dung Trinh, I. P. (2012). A New Set Of Measurements For The Materialism Scale.

World Health Organization. (2012). Global Health Observatory (GHO) Overweight. 